\title{
A "NEW NORMAL" CONCEPTUAL APPROACH; AUGMENTED REALITY (AR) TOURISM IN TERENGGANU
}

\author{
Faizal Mustapha', Fathilah Ismail ${ }^{2}$, Mohd Khairul Hafiz Muda ${ }^{3}$, Mohd Na'im Abdullah ${ }^{4}$, Mohd Saffuan \\ Yaakob $^{5}$ \& Mohd Norfaiz Kadir ${ }^{6}$ \\ 1,3,4,5 Department of Aerospace Engineering, Universiti Putra Malaysia \\ ${ }^{2}$ Faculty of Business, Economics, and Social Development, Universiti Malaysia Terengganu \\ ${ }^{6}$ Department of Control Planning, Level 14, TM Annexe 1, Jalan Pantai Baharu, 59100 Kuala Lumpur \\ (faizalms@upm.edu.my, fathilah@umt.edu.my, hafyz801@gmail.com,naimabdullah14@gmail.com, \\ saffuanyaakob@gmail.com, noorfaiz.kadir@tm.com.my)
}

\begin{abstract}
Tourism is one of the sectors that has been badly affected by the COVID-19 pandemic. Consequently, governments around the globe have taken measures to ease the effect of the resulting economic downturn on households and businesses in a bid to prolong survivability of the public. In the longer run, this tourism industry will desperately need to adapt to a post-pandemic "new normal" to sustain the income of its tourism players and operators. The alternative to coping with the new normal is to migrate from the classical model to an advanced or high-technology approach. "High-Tech" devices or tools can play an important role towards the recovery of the tourism industry following the upheaval caused by the pandemic. The new standard operating procedures (SOPs) to mitigate the spread of the disease, health consciousness and better hygiene protocols, and as well as social distancing are likely to remain in place for the foreseeable future. Touchless services delivery and investments in digital technology could facilitate an industry-wide recovery. The use of modern technology is quickly becoming a necessity for many destinations in order to stay competitive and attractive in the new norm of the tourism industry. A new form of technology that may be suitable for the tourism industry to use to regain some of its former glory is that of virtual and or Augmented Reality (AR). The aim of this paper is to give industry players an insight into the basic design of a mobile AR Tourism application for the state of Terengganu in Malaysia. Several interesting places will be selected for AR Tourism research and practice. The AR Tourism app will be designed to serve a specific purpose for the user, while multi-language functionality, ease-of-use and the capability to personalise the app are among the main requirements that need to be considered in attracting tourists and encouraging regular use among travel enthusiasts.
\end{abstract}

KEYWORDS: Tourism, Augmented Reality, AR Tourism, Covid-19, Mobile Application

\section{PURPOSE AND BACKGROUND}

In general, Augmented Reality refers to the use of computer-generated content to augment the real world, which is now largely supplemented with graphical content (Hyun et al., 2009). However, despite the fact that Augmented Reality technology has been around for more than a decade, it is still a relatively new concept in the tourism industry, and it has not yet reached its full potential. As a result, accurately defining Augmented Reality is a challenge.

Augmented Reality has been deemed to have a great potential for the tourism industry due to its ability to enhance the location (Fritz et al., 2005). Tourists are defined as those who have "little to no awareness of the area." (McKercher et al., 2003) As a result, a location-based technology that can access information 
in the immediate vicinity would be extremely beneficial to the industry. The use of Augmented Reality devices has the potential to develop the next generation of computerised tourist guides, as travelers are generally interested in their surroundings (Olsson et al., 2011).

According to Höllerer and Feiner (2004), the user interface should not only be able to pinpoint the user's location, but also provide background information on the area that might be of interest. This concept has sparked a lot of interest in developing a tourism app for mobile phones.

\section{METHODOLOGY}

The AR Application will be able to deploy a 3D model to an Augmented Reality (AR) content which is in animated 3D model input format. The deployed content will be device agnostic. The AR apps core engine can be installed on an Android or Apple mobile phone. The software will not require a custom operating system (OS) in order to make use of the content and can be installed on a standard OS for smart devices. Thus, the application can be used by any user on any smart device.

The Augmented Reality (AR) software and generation tool will be able to output to an app that the user will define. Other than that, the software and generation tool will be able to support the followings to the users:

a) Display animated slide,

b) Display video MP4 files,

c) Creating 3D, 2D, video, and text content.

Users will be able to interact with the AR content such as zoom into and out of the 3D Content. For smart devices with touch screens, user will be able to pinch their fingers together to zoom in and pull fingertips apart from a pinched position to zoom out the content. Meanwhile, for wearable head mounted displays, users will be able to zoom in and out the content by pinching their fingertips (on their right and left hands) and pulling their fingertips apart. The AR application will be able to produce unique QR codes, images and icons. These QR codes can be assigned to assets at the location. Other than that, the AR app can be linked to loT data at specific locations. Thus, a "Localisation tag" will be created via the use of QR codes, icons and images.

\section{FINDINGS}

The proposed AR Tourism App that will be implemented in Terengganu will attract more tourists. A marketing video of interesting places in Terengganu tied to the AR app should be promoted through various media channels to attract tourists. The development of this AR app will be introduced in the marketing video so that tourists can download the app and effectively start using it. Thus, enjoying tourist activity in Terengganu in the new norm of the post pandemic era. In the AR app, interesting places introduced in the promotional video will be listed so that tourists can plan their vacation before they visit the state. The AR app is also equipped with geo-location AR features for tourists to find places easily and the marker features have been added to the app to give tourists an explanation about the place and its heritage, history and other pertinent facts of interest. 


\section{CONCLUSION}

Many augmented reality apps have been developed and are still rapidly making inroads into various sectors of economy and industry. Few of the developed applications are largely used in the tourism industry and it is about time to introduce this "High-Tech" and "New-Normal" solution to the interesting views in Terengganu and in Malaysia as well.

\section{CONTRIBUTION/PRACTICAL IMPLICATIONS}

In summary, the objective of this paper is to propose the use of augmented reality apps in the tourism industry which indeed benefits its operators and key players and hopefully allow businesses affected by the deadly COVID-19 pandemic to recover and grow.

\section{REFERENCES}

Fritz, F., Susperregui, A., \& Linaza, M. T. (2005). Enhancing Cultural Tourism experiences with Augmented Reality Technologies. The Eurographics Association.

Höllerer, T. H., \& Feiner, S. K. (2004). Chapter Nine - Mobile Augmented Reality. H Karimi \& A. Hammad (Eds.)., Telegeoinformatics: Location-based computing and services. Taylor \& Francis Books Ltd., $01 / 2004$.

Hyun, M. Y., Lee, S., \& Hu, C. (2009). Mobile-mediated virtual experience in tourism: Concept, typology and applications. Journal of Vacation Marketing, 15(2), 149-164. 